Who manages pathology laboratories?

\author{
ROGER DYSON
}

In 1974 the DHSS issued circular HSC(1S)16, Organisation of Scientific and Technical Services, which provided an operational framework for the reorganised NHS and took into account some of the recommendations of the Zuckerman Report. ${ }^{1}$ Since 1974 there has been growing concern about the inadequacy of $\operatorname{HSC}(1 \mathrm{~S}) 16$, and a few laboratories have experienced difficulties in trying to operate an effective managerial structure. ${ }^{2}$ The development of scientific and technical services in the last decade may also have affected the validity of certain aspects of the Zuckerman Report.

For these reasons the Secretary of State established a departmental review, which resulted in June 1978 in a report entitled: Scientific and Technical Services in the NHS. With the report was the first draft of a new circular to give effect to the proposals of the report and to replace $\operatorname{HSC}(1 \mathrm{~S}) 16 .{ }^{4}$ The first published reactions to the circular and report make it clear that there are fundamental differences of principle in the approaches of the different professions to the problems.

\section{Headship of pathology departments}

The report proposes that each pathology department should have a Head and that ". . . because of the medical purpose of the work of the department, where there are consultants within it a consultant must be its Head.":3 The draft circular draws back from this unequivocal statement: in a footnote to paragraph 6 it indicates that " . . no specific guidance is given about the discipline from which the Head is to be selected. Because of the patient-orientated objectives of the department it is expected that when one or more consultants in the specialty are available the appointment will usually be one of these. ..." The draft circular goes on to specify, however, that " . . in other circumstances a non-medical scientist having appropriate qualifications and experience and of equivalent standing will be selected." This same phrase "equivalent standing" is used in the report in referring to the headship of departments without medical consultants.

While many pathologists are concerned about this modification by the draft circular, partly because of the uncertainties in defining "equivalent standing," the Institute of Medical Laboratory Sciences (IMLS) and the Association of Scientific, Technical and Managerial Staffs (ASTMS) remain deeply opposed to the assumption that the headship is normally a medical responsibility if there is a consultant in the department. Mr Reg Bird, national officer of ASTMS, has made it clear that scientific officers' promotion possibilities must not be limited by opportunities being reserved for any particularly favoured group and that "... if we are going to have heads of departments in pathology, we should make it abundantly clear that such posts are not exclusively reserved for consultants or their

\footnotetext{
Department of Adult Education, University o Keele

ROGER DYSON, BA, PHD, director
}

equivalent [whatever that may mean] to the exclusion of other professional staff." "5 The IMLS shares the philosophy of ASTMS in its approach to the medical profession; it does not consider the current draft circular satisfactory and believes that it "... reflects a continuation of the dominating medical influence on the Department's thinking ....," about which the IMLS has complained before. Its conclusion differs from that of ASTMS, however, in arguing that medical laboratory teams "... should have joint heads managerially responsible for the clinical and scientific functions respectively." The IMLS criticises the report for rejecting "...the logical conclusion that a district management team (DMT) type structure is required..." within which the joint heads would be separately appointed by, and responsible to, the health authority.

The report rejected the claim for joint headship, and the case against it is clearly overwhelming. A pathology department is a unitary organisation offering a specific range of services; to have the clinical and scientific parts of that service independent of one another is organisational and managerial nonsense. If a district administrator and a district finance officer refuse to co-operate as equals in a team the health authority is called in. If a consultant head of department and a senior chief medical laboratory scientific officer refuse to co-operate patients are immediately put at risk. One man must carry the final responsibility and be in total charge of the department. The case is so straightforward that one suspects the IMLS of putting their claim forward merely as a bargaining counter in the debate about the proposed draft circular.

One aspect of the report that seems to be on less certain ground is its claim that if one or more medical consultants are in post the head should always be a medical consultant. There are already situations where "... in several departments of high standing, a Top Grade Biochemist is already in post as Director/Head of a Department in which there are one or more consultants." M Many pathologists recognise the reason for these appointments, often in university departments, and a form of words will be needed that allows for this without the open-ended woolliness of the draft circular. The basic reason for the inadequacy of the draft circular on this point is identified by Association of Clinical Biochemists (ACB). The distinction between scientific and technical services is not maintained in the text and "... no good purpose is achieved by this deliberate obscurity, which confuses real differences in function between scientists and medical laboratory scientific officers, and in the services which they provide." 7 On the question of eligibility for the headship of pathology departments there are therefore fundamental differences of opinion, and a compromise that satisfies no one is an unpromising foundation for an efficient service to the patient.

\section{Job titles and responsibilities}

The two key titles introduced by the draft circular are those of head and manager. The manager is defined as someone who "... while accountable to the Head for his responsibilities should have these assigned to him in his job description by the Health Authority after consultation with the Head."

The discussions about titles and responsibilities have become intertwined because of assumptions about what titles mean in terms of responsibilities. The ACB points out that whereas in the draft circular a head is seen as superior to and responsible for a manager, in other professions in the NHS this relationship is reversed. The new district therapistmanager is responsible for heads of departments within the therapy professions. If the titles of head and manager are to be adopted there will need to be a clearly stated relationship between the two that does not obscure the head's ultimate responsibility for the total work of the department.

The draft circular is obscure. In undertaking his duties the manager is required to ". . . establish appropriate links with administrative officers and others directly as suitable..." (suitable to whom ?), and his relationship with the head is normally to be ". . that of exception reporting, and of collaboration in the development of operational planning." Although this is to be done under the general direction of the head the circular has pre-empted certain aspects of the relationship between head and manager and this is where there is obscurity. The draft circular offered the title of director instead of head and there is much less obscurity about the relationship between a director and a manager.

Unfortunately the title of director is largely unacceptable to pathologists because it might have implications for clinical freedom vis á vis the relationships between consultants within a department. Instead, the Association of Clinical Pathologists (ACP) has suggested qualifying the title of manager by specifying the extent of any general managerial responsibilities within the job title-for example, manager (MLSO training). The ACB has gone so far as to suggest the title of supervisor instead of manager. Pathologists and scientists seem united in wanting to ensure a clear and unequivocal relationship in which the manager, whatever his ultimate title, is fully and directly accountable to the head for carrying out his duties.

By contrast the IMLS deplores “... the fundamental unsoundness of the proposal that the Manager should be accountable to, instead of monitored by, the Head ..."." The IMLS is prepared to compromise on its claim for a joint headship "... only if the proposed manager has a job description specially reserving certain responsibilities to him, for which he should be accountable to the health authority while monitored for clinical purposes by the medical head." "My italics.) The IMLS insists on a full job description negotiated within each health authority listing all responsibilities and with a minimum list required within the draft circular, which "... should be much more positive and unequivocal about minimum responsibilities to be exercised by the proposed manager." 6 As with the headship, so with the title and 
responsibilities of the manager there is disagreement between the professions on points of principle.

\section{An alternative development}

It is easy to see why some pathologists are questioning the need to proceed further with the debate about a draft circular that seems to have contributed to a polarisation of thinking and approach between different professions. There are at least two reasons why the NHS and the professions concerned should persevere. A recent report has identified and measured the extent to which difficulties over the interpretation of responsibilities outlined in HSC(1S)16 are spreading." Many of these difficulties have had and are having a serious effect on patient services, and only recently there was an eight-day strike of scientific officers in Fife that related specifically to the issue of managerial responsibilities under the terms of HSC(1S)16. There has also been industrial action at Liverpool on the related question of whether or not to appoint a principal MLSO and its managerial implications. Because patient services are being affected in all these disputes the professional staff concerned should seek to achieve the widest possible agreement about how to proceed nationally. Pathologists who are completely satisfied with their own local situation and who do not want to disturb current arrangements should consider their sometimes isolated and more restricted colleagues and should realise that the settlement of some recent disputes has weakened the position of the pathologists concerned. This in itself is an encouragement to further disputes and even more difficulties in maintaining patient services.

The second reason for perseverance is that there may be an alternative way forward at national level not directly raised in the report or the draft circular because it concerns an issue that is the responsibility of the Whitley Council. The rigid dependence of the NHS on a system where numbers employed determines remuneration has encouraged the growth of the "floating" scientific officer. In order to obtain promotion and higher remuneration scientific officers have to leave their department and undertake often illdefined co-ordinating and managerial respon- sibilities across all pathology departments. Like all jobs created to make higher remuneration possible, it does not stretch or satisfy an able man and he is left to carve out a task for himself in whatever way is possible in his particular situation. Virtually all the recently reported difficulties in the management of pathology departments ${ }^{2}$ have arisen in situations where there has been a floating post of this nature in the laboratory. There are even grounds for believing now that men are being promoted to these posts because they are thought to be unsuited to the responsibilities of the most senior scientific officer within a department, and yet their post gets higher remuneration.

The floating scientific officer may be a principal MLSO where the highest-grade departmental MLSOs are senior chiefs or a senior chief MLSO where the highest-grade departmental MLSOs are chiefs: it is the floating principle that is wrong, not the grade itself. Since this concept was created there have been considerable developments in technology, staffing, and organisation that have reinforced the size and separateness of individual pathology departments, all of which strengthen the need for the most able officers to work as the most senior scientific officers within a department, and it is here that remuneration should be the highest that is available within the laboratory.

The draft circular may be moving in this direction with an obscurely worded sentence: "... where the Health Authority determines after consultation that it is necessary to assign duties covering services for a number of separate departments to one of the Managers, the Manager for these should relate similarly to each departmental Head." It is not clear whether this means that shared services will be the responsibility of one of the existing departmental managers, whether they will be the responsibility of a separate manager, or whether it means that either situation may be possible. If laboratory-wide responsibilities are shared among the most senior scientific officers in each department or if they rotate between them this at least avoids a whole-time floating post, but scientific officers will still spend valuable time on largely administrative tasks. Perhaps one solution would be to assign tasks like the day-to-day administration of the scientific officer training programme to a less senior scientific officer, leaving laboratory- wide administrative policy to the consideration of departmental heads and managers.

This could be achieved only through a restructuring of the grading criteria, and there would be common ground between the professions in seeking to achieve it. The IMLS argues that as well as numbers managed in determining remuneration ". . . there should be an alternative at all levels based on a nonmanagerial scientific contribution." " New criteria that allowed the most senior scientific officer within a department to obtain the highest grade of remuneration within his profession in the laboratory could be achieved by combining the issues of numbers managed with scientific contribution. It would reinforce the concept of the departmental team free to work in its own way within broadly defined guidelines and would relegate the business of interdepartmental administration to a more appropriate level. Given such a framework the questions about pathology laboratory management could be approached in a less partisan spirit and with fewer grounds for the polarisation of views between the professions.

\section{References}

Committee on Hospital Scientific and Technical Services, Report. London, HMSO. (Zuckerman

Dyson, R F, The Management of Pathology Laboratories. London, Association of Clinical Pathologists,

Scientific and Technical Services in the NHS. DHSS

rganisation and Management of Scientific and Technical

.

IMLS Gazette, October 1978, p 393.

lat, Association of Clinical Biochemists ACB/S/133, October 1978

\section{Correction}

\section{GP records: a simple and inexpensive} system

In the acknowledgements at the end of the above article we omitted the names of the partners of the author, Dr Christopher Maycock, for which we apologise. The acknowledgment should have contained the following sentence. "I should like to acknowledge the help of my partners, Dr A E Forbes and Dr J S Wright, without whose close co-operation the records system could not have evolved; I am particularly grateful for Dr Wright's contribution to the design of the system."

\section{Geriatrics and mental illness}

Details of consultant staffing, numbers of beds, and waiting lists in geriatrics and mental illness (adult) in England and Wales were given in response to a recent question in the Commons.

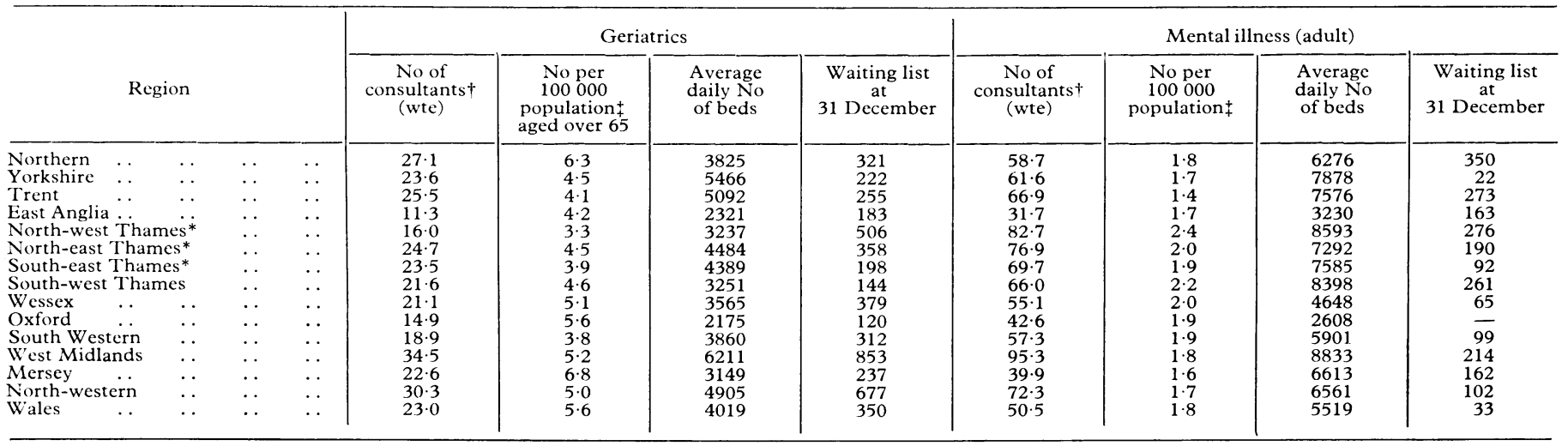

